\title{
Aplicação da técnica de REP - PCR no rastreamento de Staphylococcus aureus em sala de ordenha, para o monitoramento da qualidade do leite
}

\author{
Lea CHAPAVAL ${ }^{1}$ \\ David Henry MOON ${ }^{3}$ \\ José Elias GOMES² \\ Fábio Rodrigo DUARTE² \\ Siu Mui TSAI ${ }^{2}$
}

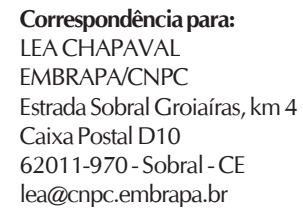

Correspondência para:

LEA CHAPAVAL

EMBRAPAVNPC

Estrada Sobral Groiaíras, km 4

Caixa Postal D10

62011-970-Sobral-CE

lea@cnpc.embrapa.br

Recebido para publicação: 31/05/2004 Aprovado para publicação: 01/06/2005

\author{
1 - Embrapa Caprinos - Sobral - CE \\ 2 - Centro de Energia Nuclear na Agricultura da Universidade de São Paulo, \\ Piracicaba - SP \\ 3 - Departamento de Genética da Escola Superior de Agricultura Luiz de \\ Queiroz da Universidade de São Paulo, Piracicaba - SP
}

\begin{abstract}
Resumo
A identificação e classificação bacteriana são de suma importância no ambiente, na indústria, na medicina veterinária, na microbiologia e na ecologia microbiana. Um número de diferentes métodos genotípicos e fenotípicos estão sendo empregados para identificação e classificação microbiana. A técnica de REP-PCR é baseada no uso de primers sintetizados a partir de sequências repetidas de DNA, chamadas de palindrômicas extragênicas repetidas (REP), e têm sido descrita como um método o qual gera impressões digitais (fingerprints) de DNA que podem diferenciar bactérias entre gêneros e espécies. Neste estudo, o método de fingerprint foi usado para Staphylococcus aureus com o objetivo de avaliar a higiene de ordenha em duas fazendas leiteiras. Foram obtidos vários fingerprints de todos os isolados coletados das diferentes fontes estudadas (mãos de ordenhadores, tetos das vacas, leite e ordenhadeira), e foram obtidos comportamentos muito similares das bandas indicando que os isolados podem ser relatados como clones epidemiológicos. Em nosso estudo, a técnica mostrou ser eficiente para a análise da similaridade entre indivíduos da mesma espécie, no caso, o Staphylococcus aureus, mostrando ser uma ferramenta útil para investigação de falhas no manejo e, em um controle mais eficiente para evitar e/ou diminuir a disseminação de microrganismos causadores de sérias enfermidades em humanos e em animais, que podem ser transmitidas através de produtos como o leite e seus derivados.
\end{abstract}

\section{Introdução}

Sistemas de tipagem epidemiológica podem ser usados para investigações de surtos, para confirmar e delinear comportamentos de transmissão de um ou mais clones epidêmicos, para testar hipóteses sobre fontes e veículos de transmissão destes clones e para monitorar reservatórios de organismos epidêmicos ${ }^{1}$. A tipagem também contribui para a vigilância epi-demiológica e avaliação de medidas de controle, através da documentação da prevalência através do tempo e circulação de clones epidêmicos em
Palavras- chave: Staphylococus aureus. Higiene de ordenha. Epidemiologia molecular. Fingerprint. populações infectadas ${ }^{2,3}$.

A premissa básica para a tipagem epidemiológica é que isolados (agentes infecciosos) que são parte da mesma cadeia de transmissão são relatados como clones, que são a progênie da mesma célula ancestral. Isolados relatados como clones, significantemente, exibem muitos caracteres similares que aqueles não relatados, chamados marcadores epidemiológicos que podem ser registrados através de sistemas de tipagem os quais são desenhados para otimizar a discriminação entre isolados de interesse patogênicos epidemiologicamente relatados 
ou não ${ }^{2,3}$.

Um número de diferentes métodos genotípicos e fenotípicos estão sendo empregados para identificação e classificação microbiana, de crucial importância no ambiente, na indístria, na medicina veterinária e na ecologia microbiama ${ }^{4}$. Cada um destes métodos permite um certo nível de classificação filogenética, para gênero, espécies e biovar de uma cepa ${ }^{5}$.

O método referido como REP-PCR, "impressão digital" do genoma, uma técnica baseada na amplificação do DNA, é tida como uma técnica extremamente confiável, reprodútivel, rápida e altamente discriminatória ${ }^{6,4}$. Esta técnica faz uso de primers de DNA complementares àqueles de ocorrência natural, altamente conservados, com seqüências repetitivas de DNA e presente em múltiplas cópias do genoma da maioria das bactérias Gram negativas e em muitas bactérias Gram positivas ${ }^{7}$. As identidades genômicas geradas pela técnica de REP-PCR permite a diferenciação em nível de espécies, subespécies e cepa ${ }^{8}$.

Dentre os microrganismos Gram positivos, os Staphylococcus destacam-se como importante grupo, cuja presença se faz observar sobretudo na pele e mucosas do homem estendendo-se, de forma generalizada, a animais de sangue quente $\mathrm{e}^{9,10,11,12}$. Ainda que possa colonizar-se em diferentes regiões do organismo, existe um consenso de que o maior reservatório para $\mathrm{S}$. aureus sejam as fossas nasais. A presença na mão e outras superfícies, resulta de vínculo epidemiológico decorrente de disseminação a partir dos principais sítios ${ }^{13,14}$.

Assim o portador de Staphylococcus enterotoxigênicos, enquanto manipulador de alimentos ou trabalhador de sala de ordenha, representa indiscutível elo na cadeia epidemiológica da intoxicação alimen$\operatorname{tar}^{15,16,17,18,19,20}$. Em animais, diversos trabalhos exemplificam a incidência particularizada de Staphylococcus no úbere de vacas e, conse-qüentemente, no leite cru procedentes de fêmeas sadias e/ou com mastite. O leite, nestas condições, poderá ser, indevidamente, o que ocorre na maioria das vezes, incor-porado ao leite de fêmeas normais, nas usinas de processamento $^{21,22,11,23,24,25,26,27,28}$. Maior enterotoxigenicidade foi revelada a partir de amostras coletadas da superfície do úbere, tetos e leite, representando real perigo a saúde públi$\mathrm{ca}^{26,29,23,30,31}$.

O presente trabalho teve como objetivo avaliar a técnica de REP-PCR no monitoramento da qualidade do leite de vacas, através do rastreamento de Staphylococcus aureus na linha de produção de leite, avaliando as mãos dos ordenhadores, teteiras, úbere dos animais e leite in natura como veículos de contaminação.

\section{Materiais e Métodos}

Cepas bacterianas. Para a obtenção das colônias usadas no presente estudo, foram utilizadas duas fazendas com diferentes aspectos de manejo, chamadas de A e B. A fazenda $\mathrm{A}$ mostrou boas práticas durante $\mathrm{O}$ manejo de ordenha. Desta fazenda foram obtidas 64 amostras, sendo que estas foram dividas entre amostras de leite coletadas no período inicial da ordenha, no meio e no final desta, swabs de teteiras e mãos dos ordenhadores coletados antes e durante a ordenha dos animais (Tabela 1). $\mathrm{Na}$ fazenda $\mathrm{B}$, que mostrou práticas incorretas durante omanejo de ordenha, foram coletadas 18 amostras, divididas e amostras de leite coletadas no início e no meio da ordenha e amostras de swabs das teteiras e das mão do ordenhador no meio da ordenha (Tabela 2). As amostras foram coletadas usando técnicas assépticas e acondicionadas usando protocolos padrão. As culturas que mostraram-se características em ágar Baird Paker (OXOIDÒ, England) foram inoculadas, em placa de crescimento com 96 poços, em $1 \mathrm{ml}$ de caldo cérebro coração (BHI) durante 18 horas a $37^{\circ} \mathrm{C}(10$ colônias identificadas como características, para cada amostra semeada), priorizando a extração do DNA da população a ser estudada. Todas as cepas foram testadas para 
morfologia e bioquímicamente para função através do kit comercial API Staph (bioMérieuxÒ), coagulase livre (Dry Spot OXOIDÒ, England), produção de termonuclease, coloração de Gram, catalase e capacidade de lisar hemáceas em sangue de ovinos.

Extração de DNA da população bacteriana. A extração de DNA das cepas bacterianas foi realizada segundo o protocolo proposto por Doyle e Doyle ${ }^{32}$, e adaptado em nosso laboratório para este estudo.

Primers. A síntese de oligonucleotídeos foi elaborada pela Promicro Comércio e Representações de Produtos Microbiológicos Ltda (São Paulo, Brasil). As seqüências utilizadas foram as seguintes

REP - 1 5' NNN NCG NCG NAC TCC NGG C 3'

REP - 2 5' NCG NCT TAT CNG

GCC TAC TAC 3'

Condições de PCR. O PCR foi realizado com $25 \mathrm{ml}$ do volume total incluindo $5 \mathrm{ml}$ do DNA alvo (20 a $90 \mathrm{ng} /$ $\mathrm{ml})$. Os componentes do master mix (GIBCO BRL - Life Technologies, Inc., MD, U.S.A.) foram misturados conforme as instruções do fabricante com a utilização de um máximo de $5 \mathrm{ml}$ do DNA alvo extraído a partir da metodologia usada. Os DNA alvo foram amplificados em termociclador Gene AmpÒ PCR System 9700 (Perkim Elmer) com os seguintes ciclos: desnaturação inicial $95^{\circ} \mathrm{C}$ por 6 minutos seguida por 30 ciclos de amplificação (desnaturação a $94^{\circ} \mathrm{C}$ por 1 minuto, anelamento a $40^{\circ} \mathrm{C}$ por 1 minuto, polimerização a $65^{\circ} \mathrm{C}$ por 8 minutos), terminando com a polimerização final a $65^{\circ} \mathrm{C}$ por 7 minutos.

Detecção dos produtos de PCR. $8 \mathrm{ml}$ do produto amplificado pela reação de PCR foi analisado através da eletroforese em gel de agarose 2\% (GIBCO BRL - Life Technologies, Inc., MD, U.S.A.) em TAE 1x (para $50 \mathrm{X}, 242 \mathrm{~g}$ Tris; 37,2 g EDTA [Na $]$, $800 \mathrm{ml}$ de água MilliQ autoclavada, $57 \%$ de ácido acético, $\mathrm{pH} 8,1)$ e um padrão molecular 100bp (GIBCO BRL - Life Technologies, Inc., MD, U.S.A.) foi usado como marcador molecular. A eletroforese foi realizada em cuba eletroforética Pharmacia Biotech (max submarine unit HE $99 \mathrm{X}$ ), com fonte Pharmacia Biotech (EPS 300) nas condições de $70 \mathrm{~V}$ por 2 horas.

Inspeção visual das "identidades" da população bacteriana. A identidade de cada população foi comparada com as outras populações estudadas por somente um observador. O tamanho molecular das bandas amplificadas foram analisadas através de comparação com um padrão molecular de $1 \mathrm{~kb}$ DNA ladder (GIBCO BRL - Life Technologies, Inc., MD, U.S.A.) Os perfis das 11 primeiras bandas foram considerados altamente similares quando todas as bandas visíveis dos isolados possuíam a mesma distância aparente de migração. Quando não houve migração de bandas semelhante, os isolados forma considerados diferentes através da inspeção visual.

Análise computacional das identidades da população bacteriana. O programa usado para a análise da similaridade genética das populações bacterianas deste estudo foi o NTSYS Numerical Taxonomy and Multivariate Analysis System, versão NTSYSpc 2.0.

\section{Resultados e Discussão}

Os géis de agarose obtidos para as análises da similaridade genética estão representados pela figura $1 \mathrm{a}, 1 \mathrm{~b}, 1 \mathrm{c}$ para a Fazenda A e pela figura 2 para a Fazenda B. Para a análise de similaridade, as amostras (populações) foram divididas em grupos (cores) para melhor compreensão e discussão dos resultados. Nos dendogramas (Figura 3 e 4), cores iguais representam grupos com similaridade e de acordo com a escala representada abaixo das figuras (Escala de Jaccard), quanto mais próximo do valor 1,00, mais similares são as amostras. As tabelas 1 e 2 mostram os números das amostras e seu respectivo significado (leite do início, meio e fim da ordenha e swabs 


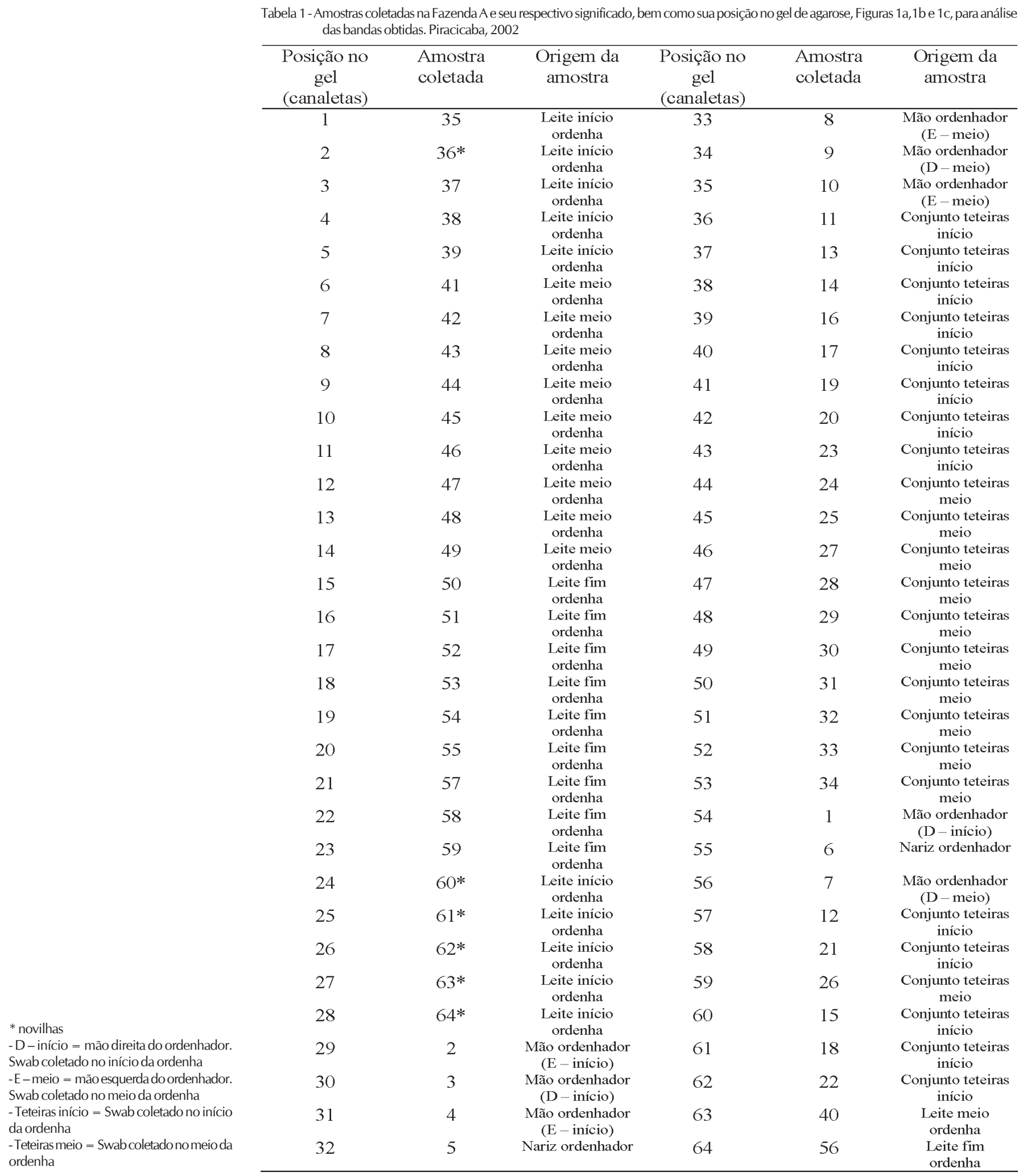


das mãos dos ordenhadores e das teteiras do início e meio da ordenha).

O método de "fingerprint" baseado na PCR, que utiliza primers de seqüências consenso para seqüências extragênicas palindrômicas (REP), encontrada nos cromossomos de muitas bactérias têm se mostrado aplicável a uma gama de bactérias $^{33,34,35,36,37,38,39,28,40,41,42,43}$.

Em nosso estudo, complexos modelos de identidades, "fingerprints", foram obtidos para todos os isolados estudados através da utilização da REP-PCR. Em geral, o modelo das bandas dos isolados das diferentes fontes (humana e animal, bem como do maquinário) foram muito similares, e os dados indicam que os isolados são estreitamente relacionados. Foram similares porém nem sempre idênticos. Aproximadamente dois quartos das bandas foram comuns para $80 \%$ dos isolados da Fazenda A e, até três quatros para $90 \%$ dos isolados da Fazenda B. O tamanho dos produtos (bandas) da PCR alcançaram pequenas bandas menores que $300 \mathrm{bp}$, até bandas de 10.000bp.

Após a inspeção visual (os dados foram assinalados manualmente), os dados foram submetidos ao programa computacional NTSYSpc 2.0 e coeficientes de

Tabela 2-Amostras coletadas na Fazenda B e seu respectivo significado, bem como sua posição no gel de agarose, figura 2, para análise das bandas obtidas. Piracicaba, 2002

\begin{tabular}{ccc}
\hline $\begin{array}{c}\text { Posição no gel } \\
\text { (canaleta) }\end{array}$ & Amostra coletada & Origem da amostra \\
\hline 1 & 1 & Leite início ordenha \\
2 & 2 & Leite início ordenha \\
3 & 3 & Leite início ordenha \\
4 & 4 & Leite início ordenha \\
5 & 5 & Leite início ordenha \\
6 & 6 & Leite início ordenha \\
7 & 7 & Leite início ordenha \\
8 & 8 & Leite início ordenha \\
23 & 9 & Leite início ordenha \\
24 & 10 & Leite início ordenha \\
9 & 12 & Leite meio ordenha \\
17 & 13 & Leite meio ordenha \\
10 & 14 & Leite meio ordenha \\
11 & 15 & Leite meio ordenha \\
12 & 16 & Leite meio ordenha \\
13 & 17 & Leite meio ordenha \\
14 & 18 & Leite meio ordenha \\
15 & 20 & Leite meio ordenha \\
19 & 21 & Teteira 1 \\
20 & 22 & Teteira 2 \\
21 & 23 & Teteira 3 \\
22 & 24 & Teteira 4 \\
16 & 25 & Mão E ordenhador \\
18 & 26 &
\end{tabular}


similaridade de Jaccard foram calculados para as identidades geradas através do REPPCR, individualmente e para grupos de dados combinados.

A identidade ("fingerprint") das 64 famílias de Staphylococcus aureus, pertencentes a Fazenda A, foi determinada, o resultado do perfil obtido através da PCR foi analisado e decisões sobre quais os perfis seriam altamente similares foram feitos com base na inspeção visual e podem ser observados nas figuras $1 \mathrm{a}, 1 \mathrm{~b}$ e $1 \mathrm{c}$. A identidade dos produtos gerados para os 18 isolados da Fazenda B pode ser visto na figura 2.

Quando comparados visualmente, muitos perfis de DNA se mostraram altamente similares em termos de número e posições relativas das bandas, mas após uma inspeção mais apurada, pequenas diferenças na posição de algumas bandas foram notadas. Os dendogramas gerados a partir dos dados obtidos podem ser visualizados através das figura 3, para a Fazenda A, e figura 4, para a Fazenda B. Os números ao lado das ramificações dos dendogramas indicam a origem da população bacteriana estudada e podem ser localizados através das tabelas 1 e 2 .

A figura 3 mostra o dendograma gerado a partir dos dados obtidos da Fazenda A. Foi obtido um dendograma mais complexo, porém a divisão deste e sua representação através de diferentes cores facilitou a análise. O grupo azul, composto das amostras 1 (mão direita do ordenhador), 22 e 23 (amostras obtidas das teteiras no inicio da ordenha), mostra haver falhas na higienização do equipamento. O grupo rosa, basicamente composto de amostras de teteiras no início da ordenha $(12,13$ e 15), mostra que realmente existe similaridade entre os microrganismos encontrados neste local, apontando para falhas no circuito de limpeza. O grupo em verde, composto pela maioria das amostras, tem em sua composição amostras de leite do início da ordenha em conjunto com amostras do leite coletado no final da ordenha $e$ microrganismos isolados da teteira durante o meio da ordenha, mostrando similaridade de até $60 \%$ entre estas. Nesta situação, observa-se a presença de vários clones $(100 \%$ de similaridade) e pode-se inferir através da similaridade genética, que o leite inicialmente contaminado passa pelo maquinário, contaminando a linha de leite e chegando aos animais ordenhados ao final do período. Microrganismos do grupo marrom são pertencentes a amostras oriundas das teteiras do início $(14,17,18,19)$ e teteiras do meio da ordenha $(27,32,33)$ e uma amostra, de número 36 (leite coletado no início da ordenha) mostra quase $80 \%$ de similaridade em relação as amostras citadas anteriormente. Pelo menos uma amostra de leite coletada no início da ordenha se encontra presente nos demais grupos, indicando uma contaminação desencadeada pela limpeza incorreta do maquinário de ordenha e iniciando assim, contaminação em cascata.

$\mathrm{Na}$ figura 4, Fazenda B, o dendograma foi dividido em 3 grupos distintos e também foram considerados similares, aqueles indivíduos que se encontravam na faixa de 0,50 e 1,00, segundo o coeficiente de similaridade de Jaccard. No grupo azul, foi encontrada similaridade de aproximadamente 75 e $80 \%$ para as populações 18 (mão esquerda do ordenhador) e 19 (teteira), respectivamente, em relação as populações 3 e 4 e 1 e 2 (amostras de leite do início da ordenha), que se mostraram idênticas (coeficiente 1,00). Ao ser verificada a origem das amostras, mostrou-se que as amostras originadas do leite do início da ordenha poderiam ter dado origem a contaminação no momento de ordenha. Se observarmos o grupo laranja, podemos notar o mesmo comportamento, uma vez que algumas amostras de leite inicial (i.e. 5, 6, 24, etc.) estão presentes e possuem coeficientes de similaridade em torno de $75 \%$ com as outras amostras (mão, teteiras e leite coletado no meio da ordenha). Através desta breve análise podemos presumir que a contaminação bacteriana é oriunda dos 


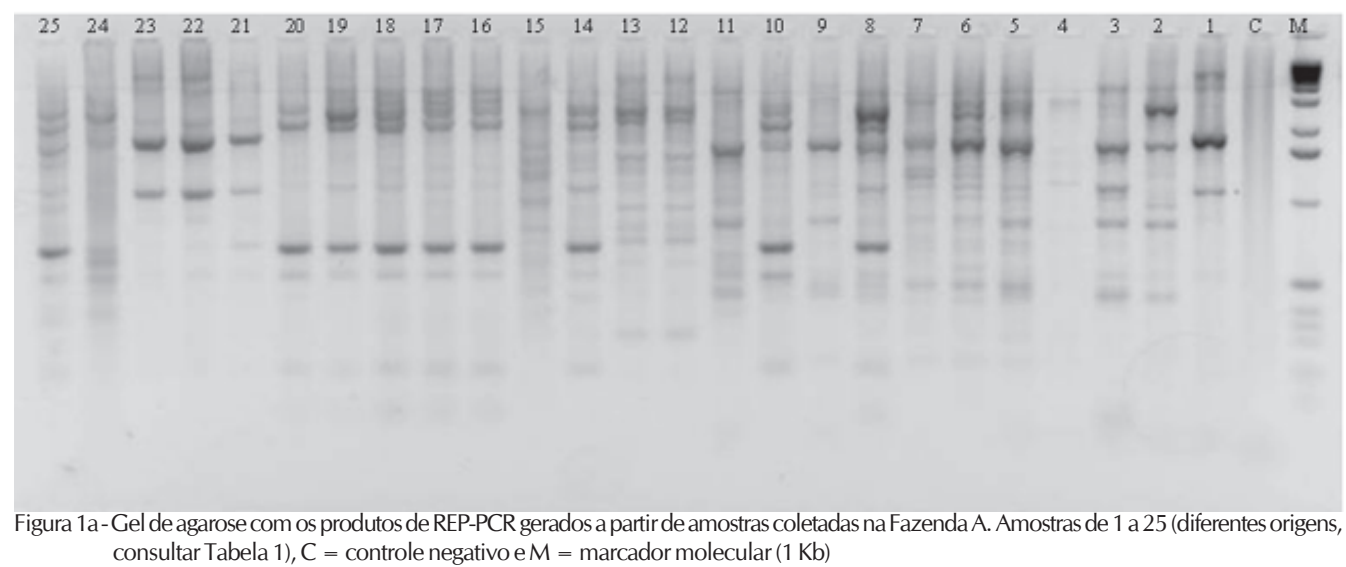
consultar Tabela 1$), \mathrm{C}=$ controle negativo e $\mathrm{M}=$ marcador molecular $(1 \mathrm{~Kb})$

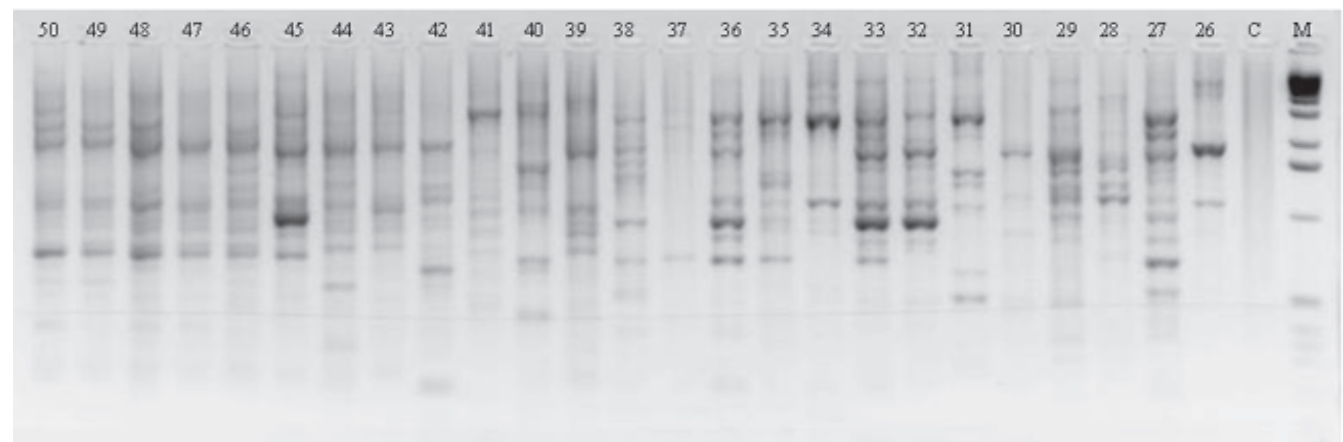

Figura 1b-Gel de agarose com os produtos de REP-PCR gerados a partir de amostras coletadas na Fazenda A. Amostras de 26 a 50 (diferentes origens, consultar Tabela 1), $\mathrm{C}$ = controle negativo e $\mathrm{M}$ = marcador molecular (1 Kb)

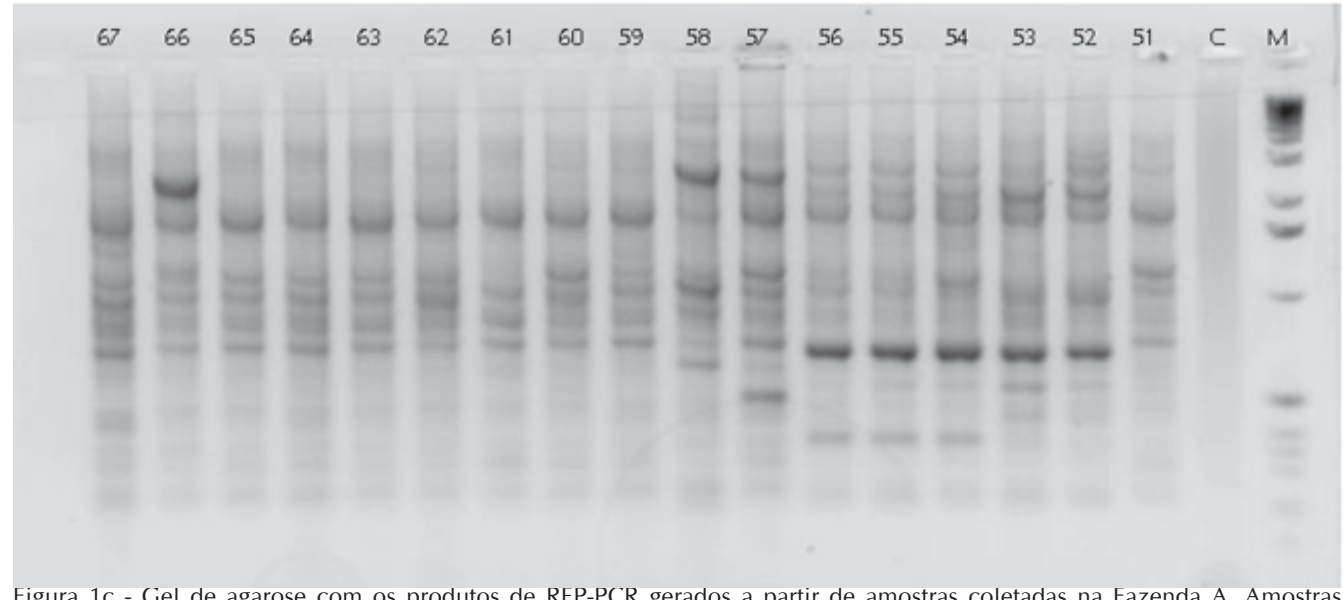
de 51 a 67 (diferentes origens, consultar Tabela 1), $\mathrm{C}=$ controle negativo e $\mathrm{M}=$ marcador molecular $(1 \mathrm{~Kb})$

animais e que procedimentos de higienização dos mesmos devem novamente avaliados, ou seja uma rotina de limpeza de tetos, bem como a eficácia dos desinfetantes devem ser revistos.

Para os dois dendogramas analisados, devemos notar, também e com igual importância, a similaridade entre os grupos, que apesar de baixa (abaixo de 0,5) em algumas situações chega em $60 \%$, portanto deve ser considerada a hipótese de termos populações similares geneticamente.

Vários autores têm usado a técnica de REPPCR para análise da diversidade/similaridade 


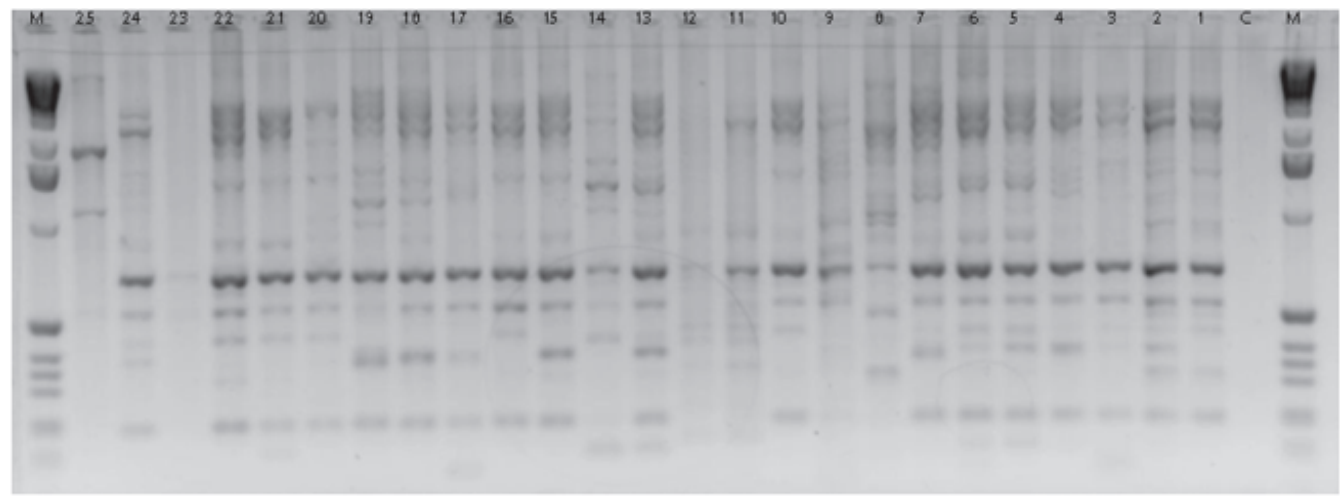

Figura 2 - Gel de agarose com os produtos de REP-PCR gerados a partir de amostras coletadas na Fazenda B. Amostras de 1 a 25 (diferentes origens, consultar Tabela 2), $\mathrm{C}=$ controle negativo e $\mathrm{M}=$ marcador molecular $(1 \mathrm{~Kb})$

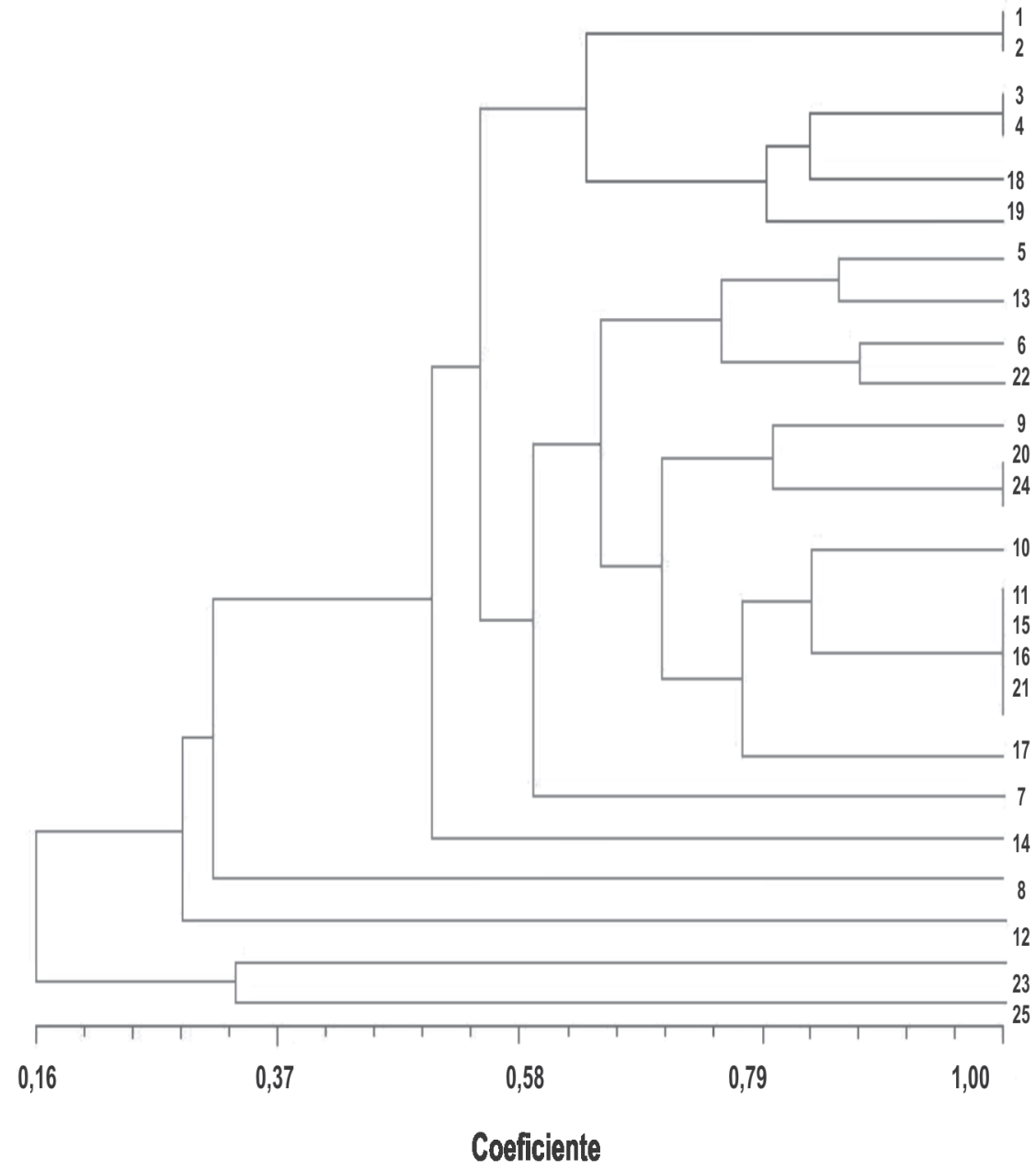

Figura 4 - Dendograma gerado a partir dos dados obtidos da Fazenda B. Números representados com cores iguais mostram similaridade genética. Os números do eixo y indicam o Coeficiente de Jaccard 


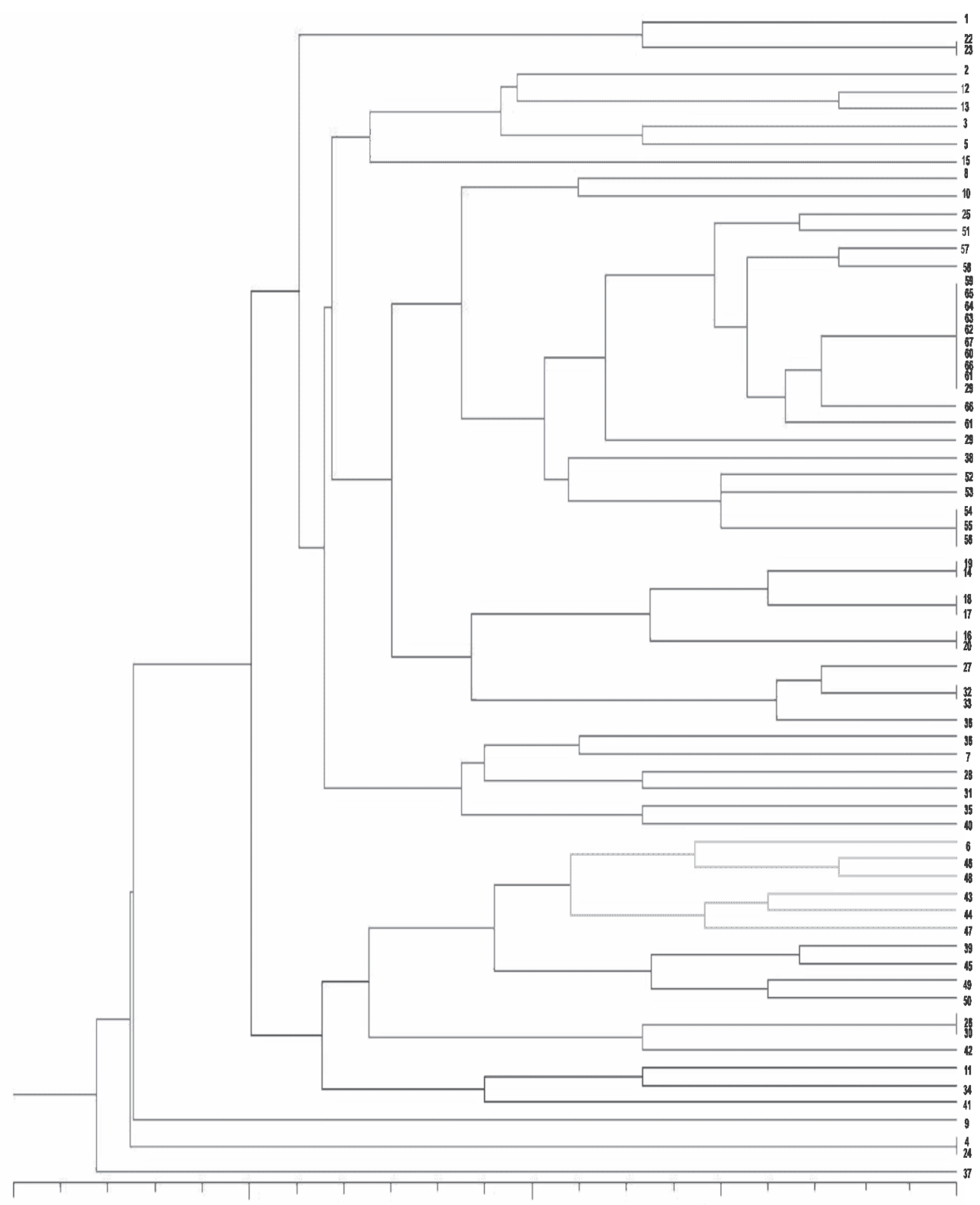

0,00

Figura 3 - Dendograma gerado a partir dos dados obtidos da Fazenda A. Números representados com cores iguais mostram similaridade genética. Os números do eixo y indicam o Coeficiente de Jaccard

entre indivíduos da mesma espécie ${ }^{44,45,28} \mathrm{e}$ indivíduos de espécies diferentes ${ }^{46}$, bem como para a diferenciação entre as diferentes origens de microrganismos ${ }^{47}$.

\section{Conclusões}

No presente estudo, a técnica mostrou ser eficiente para a análise da 
similaridade entre indivíduos da mesma espécie, no caso, Staphylococcus aureus. A técnica poderá vir a ser mais explorada para estudos de epidemiologia molecular como este, pois mostrou ser uma ferramenta útil para investigação de falhas no manejo e, para elaboração de métodos de controle mais eficientes para evitar e/ou diminuir a disseminação de microrganismos causadores de sérias enfermidades em humanos e em animais, que podem ser transmitidas através de produtos como o leite e seus derivados.

\title{
Using the REP-PCR technic in the tracking of Staphylococcus aureus in milking room, for milk quality production
}

\begin{abstract}
The identification and classification of bacteria are of crucial importance in environmental, industrial, veterinary, microbiology and microbial ecology. A number of different phenotypic and genotypic methods are presently being employed for microbial identification and classification. Repetitive-element PCR (Rep-PCR) with primers based on repetitive extragenic palindromic (REP) repeated DNA sequences is a recently described method which generates DNA fingerprints that descriminate between bacterial species and strains. In this study, this method was used for genomic fingerprinting of Staphylococcus aureus in control of hygiene in milk line production on two farms. Complex fingerprinting patterns were obtained for all isolates from different sources (milking handlers, cows teats, milk and milk machine) were very similar, and the data indicated that the isolated were closely related. In our study, this technic shows to be usefull for investigation in fails on milk line production and for more efficient control for patogenic microrganisms that cause serious illness in humans and animals.
\end{abstract}

\section{Referências}

01 STRUELENS, M. J. Molecular epidemiologic typing systems of bacterial pathogens: current issues and perspectives. Memórias do Instituto Oswaldo Cruz, v. 93, n. 5, p. 581-585, 1998.

02 MASLOW, J.; MULLIGAN, M. E. Epidemiologic typing systems. Infection Control and Hospital Epidemiology, v. 17, p. 595-604, 1996.

03 STRUELENS, M. J. et al. Consensus guidelines for appropriate use and evaluation of microbial epidemiologic typing systems. Clinical Microbiology and Infection, v. 2, p. 2-11, 1996.

04 LOUWS, F. J.; SCHNEIDER, M.; de BRUJIN, F. J. In.: TORANZOS, G. (Ed.), Nucleic acid amplification methods for the analisys of environmental samples. Technomic Publ. Co., p. 63-94, 1996.

05 AKKERMANS, A. D. L.; VAN ELSAS, J. D.; de BRUJIN, F. J. Molecular ecology manual. Dordrecht, The Netherlands: Kluwer Academic Publ. 1995. p. 1488.

06 VERSALOVICK, J.; SCHNEIDER, M.; de BRUJIN, F. J.; LUPSKI, J. R. Methods in Molecular and Cellular
Key-words: Staphylococcus aureus. Milking hygiene. Molecular epidemiology. Fingerprint.
Biology, v. 5, p. 25-40, 1994.

07 LUPSKI, J. R.; WEINSTOCK, G. M. Short, interspersed repetitive DNA sequences in procaryotic genomes. Journal of Bacteriology., v. 174, p. 45254529, 1992.

08 RADEMAKER, J. L. W.; DE BRUJIN, F. J. Characterizarion and classification of microbes by RepPCR genomic fingerprint and computer-assisted pattern analysis. Available from: http://www.msu.edu/ asci/debrujin/dna.htm >. Access: 28 Feb. 2003

09 KLOOS, W. E.; MUSSELWIHTE, M. S. Distribuition and persistence of Staphylococcus and Micrococcus species and other aerobic bacteria in human skin. Applied Microbiology, v. 30, n. 3, p. 381-395, 1975.

10 KLOSS, W. E.; SCHLEIFER, K. H.; SMITH, R. F. Characterization of Staphylococcus sciuri sp. nov. and its subspecies. International Journal of Systematic Bacteriology, v. 26, n. 1, p. 22-37, 1976.

11 KLOOS, W. E. Natural populations of the genus Staphylococcus. Annual Review of Microbiology, v. 34, p. 559-592, 1980.

12 KLOOS, W. E.; SCHLEIFER, K. H. Genus IV. Staphylococcus Rosenbach 1884, 18AL, (NOM. cons. Opin. 17 Jud. Comm. 1958, 153). In: SNEATH, Peter 
H. A. etal. (Ed.) Bergey's manual of systematic bacteriology. Baltimore: Williams \& Wilkins.1986. v. 2, p. 1013-1035.

13 MALAKI, M.; KOHNEHSHAHRI, M.; GHARAGOZLOO, R. Bacteriophage typing of staphylococci isolated from foodstuffs anf food handlers in Tehran. Journal of Milk and Food Technology, v. 36, n. 5, p. 262-271, 1973.

14 RADDI, M. S. G.; LEITE, C. Q. F.; MENDONÇA, C. P. Staphylococcus aureus: portadores entre amnipuladores de alimentos. Revista Saúde Pública, v. 22, n. 1, p. 36-40, 1988

15 BRYAN, F. L. Factors that contribute to outbreaks of foodborne disease. Journal of Food Protection, v. 41, p. 816-827, 1978.

16 BRYAN, F. L. Foodborne disasesin the United State associate with meat and poultry. Journal of Food Protection, v. 43, p. 140-150, 1980.

17 IARIA, S. T.; FURLANETO, S. M. P.; CAMPOS, M. L. C. Pesquisa de Staphylococcus aureus enterotoxigênico nas fossas nasais de manipuladores de alimentos em hospitais, São Paulo, 1976. Revista Saúde Pública, v. 14, p. 93-100, 1980.

18 BERGDOLL, M. S. Staphylococcus aureus. In: Doyle, M. P. (Ed.) Foodborne bacterial pathogens. Marcel Dekker, 1989. New York: p. 463-523.

19 CRUICKSHANK, J. G. Food handlers and food poisoning. Training programmes are the best. British Medical Journal, v. 300, n. 6719, p. 207-208, 1990.

20 TRANTER, H. S. Food borne ilness. Foodborne staphylococcal ilness. Lancet, v. 27, p. 1044-1046, 1990.

$21 \mathrm{SMITH}$, M. C.; ROGUINSKI, M. Mastitis and other diseases of the goat's udder. Journal of the American Veterinary Medical Association, v. 171, p. 1241-1248, 1977.

22 MARDH, P. A.; HOVELIUS, B.; NILSSON, P. O Coagulase negative, novobiocin resistant staphylococci on the skin of animals and man, on meat and in milk. Acta Veterinaria Scandinavica, v. 19, p. 243-253, 1978.

23 SHELDRAKE, R. I.; HOARE, T. R. J.; WOODHOUSE, V. E. Relationships of somatic cell count and cell volume analisys of goat's milk to intramammary infection with coagulase-negative staphylococci. Journal of Dairy Research, v. 48, p. 393-403, 1981.

24 LERONDELLE, C.; POUTREL, B. Characteristics of nonclinical mammary infections of goats. Annales de Recherches Veteinaires. v. 15, p. 105-112, 1984.

25 POUTREL, B. Udder infection of goats by coagulase negative Staphylococci. Veterinary Microbiology, v. 9, p. 131-137, 1984.

26 HARVEY, J.; GILMOUR, A. Application of current methods for isolation and identification of staphylococci in raw bovine milk. Journal of Applied Bacteriology, $v$. 59, p. 207-221, 1985.

27 DEVRIESE, L. A.; SCHLEIFER, K. H.; ADEGOKE, G. O. Identification of coagulase negative staphylococci from farm animals. Journal of Applied Bacteriology, v. 55 , p. $45-55,1985$

28 NIEDBACH, J.; BALDY-CHUDZIC, K.; STOSIK, M. Rep-PCR fingerprinting as a tool for the analysis of genomic diversity of Escherichia coli strains isolated from a water environment. Cellular and Molecular Biology Letters, p. 309, 2000.

29 De BUYSER, M. L.; DILASSER, F.; HUMMEL, R. et al. Enterotoxin and toxic shock syndrome toxin-1 production by staphylococci isolated from goat's milk. International Journal of Food Microbiology, v. 5, p. 301-309, 1987.

30 VALLE, J.; GOMEZ-LUCIA, E.; PIRIZ, S. et al. Enterotoxin production by staphylococcal isolated from healthy goats. Applied and Environmental Microbiology, v. 56, n. 5 , p. $1323-1326,1990$

31 BAUTISTA, L.; BERMEJO, M. P.; NUÑEZ, M. Seasonal variation and characterization of Micrococcaceae present in ewe's raw milk. Journal of Dairy Research, v. 53, p. 1-5, 1986.

32 DOYLE, J. J. T.; DOYLE, J. L, 1990. Isolation of plant DNA from fresh tissue. Focus, 12:13-18, 2001.

33 DE BRUIJIN, F. J. Use of repetitive (repetitive extragenic palindromic and enterocaterial repeitive intergenic consensus) sequences and the polymerase chain reaction to fingerprint the genomos of Rizobium meliloti isolates and other soil bacteria. Applied Environmental Microbiology, v. 58, p. 2180-2187, 1992.

34 JOY-GUILLOU, M. L.; BERGOGNE-BÉRÉZIN, E.; VIEU, J. F. A study of the relationships between antibiotic resistance phenotypes, phage-typing and biotyping of 117 clinical isolates if Acinetobacter spp. The Journal of Hospital Infection, v. 16, p. 49-58, 1990.

35 DIJKSHOORN, L.; AUCKEN, H. M.; GERNERSMIDT, P.; KAUFMANN, M. E.; URSING, J.; PITT, T. L. Correlation of typing methods for Acinetobacter isolates from hospital outbreaks. Journal of Clinical Microbiology, v. 31, p. 702-705, 1993.

36 GERNER-SMIDT, P. Frequency of plasmid in strains of Acinetobacter calcoaceticus. The Journal of Hospital Infection, v. 14, p. 23-28, 1989.

37 GERNER-SMIDT, P. Ribotyping of the Acinetobacter calcoaceticus-Acinetobacter baumannii complex. Journal of Clinical Microbiology, v. 30, p. 2680-2685, 1992.

38 GOUBY, A.; CARLES-NURIT, M.; BOUZIGES, N.; BOURG, G.; MESNARD, R.; BOUVET, P. J. M. Use of pulse-field electrophoresis for investigation of hospital 
outbreaks of Acinetobacter baumannii. Journal of Clinical Microbiology, v. 30, p. 1588-1591, 1992.

39 GRÄSER, Y.; KLARE, I.; HALLE, E.; GANTERBERG, R.; BUCHHOLTZ, P.; JACOBI, H. D.; PRESBER, W.; SCHÖNIAN, G. Epidemiological study of na Acinetobacter baumannii outbreak by using polymerase chain reaction fingerprinting. Journal of Clinical Microbiology, v. 31, p. 2417-2420, 1993.

40 VERSALOVICK, J.; KOEUTH, T.; LUPSKI, J. R. Distribuition of repetitive DNA sequence in eubacteria na application to fingerprint of bacterial genomes. Nucleic Acids Research, v. 19, p. 6823-6831, 1991.

41 VERSALOVICK, J.; KOEUTH, T.; LUPSKI, J. R. Quality control for bacterial inhibition assays: DNA fingerprinting of microorganisms by rep-PCR. Screening, v. 1, p. 175-183, 1992

42 VOGT, P. Potencial genetic functions of tandemly repeated DNA sequence blocks in the human genome are based on a high conserved "chromatin foldin code". Human genetics, v. 84, p. 301-336, 1990.

43 WOODS, C. R.; VERSALOVICK, J.; KOEUTH, T.; LUPSKI, J. R. Analisys of relationships among isolates of Citrobacter diversus by using DNA fingerprints Journal of Clinical Microbiology, v. 30, p. 2921-2929, 1992.

44 RODRIGUEZ-BARRADAS, M. C.; HAMILL, R. J.; HOUSTON, E. D.; GEORGHIOU, P. R.; CLARRIDGE, J. E.; REGNERY, R. L.; KOEHLER, J. E. Genomic fingerprinting of Bartonella species by repetitive element PCR for distinguishing species and isolates. Journal of Clinical Microbiology, v. 33, n. 5, p. 1089-1093, 1995.

45 SNELLING, A. M.; GERNER-SMIDT, P.; HAWKEY, P. M.; HERITAGE, J.; PARNELL, P.; PORTER, C.; BODENHAM. A. R.; INGLIS, T. Validation of use of whole-cell repetitive extragenic palindromic sequencebased PCR (REP-PCR) for typing strains belonging to the Acinetobacter calcoaceticus-Acinetobacter baumanni. Complex aplication of the method to the investigation of a hospital outbreak. Journal of Clinical Microbiology, v. 34, n. 5, p. 1193-1202, 1996.

46 KIM, K. S.; SEO, H. A.; OH, C. Y.; LEE, C. Comparison of genetic diversities among five foodborne pathogenic genera using ERC and REP-PCR. Session 59F, Food Microbiology: Foodborne Pathogens. 1ft Annual Meeting - New Orleans, Louisiana, 2001.

47 DOMBEK, P. E.; JOHNSON, L. K.; ZIMMERLEY, S. T.; SADOWISKY, M. J. Use os repetitive DNA sequences and the PCR to differentiate Escherichia coli isolates from human and animal sources. Applied Environmental Microbiology, v. 66, n. 6, p. 2572-2577, 2000.

48 NADIR, E.; MARGALI, H.; GALLILY, T.; BENSASSON, S. S. Microsatelite spreading in the human genome:evolucionary mechanisms and structural implications. Procedings of the National Academy Sciences of the United States of America, v. 93, p. 6470-6475, 1996.
49 PEREIRA, M. J.; CARMO, L. S.; SANTOS, E. J. et al. Enterotoxin $\mathrm{H}$ staphylococcal food poisoning. Journal of Food Protection, v. 59, n. 5, p. 559-561, 1996. 